\title{
Evidências preliminares de talento musical em crianças na educação básica
}

\author{
Preliminary evidences of musical talent in basic \\ education children
}

\author{
iD Fabiana Oliveira Koga ${ }^{1}$ \\ fabianapsicopedagogiamusical@gmail.com
}

iD (9) Rosemeire de Arauljo Rangni²

rose.rangni@uol.com.br

\begin{abstract}
Resumo: $O$ talento musical pode se manifestar em diferentes pessoas, em diferentes realidades sociais e econômicas e fases da vida. A legislação prevê a identificação, cadastramento e atendimento educacional especializado ao talentoso musical. Assim, o objetivo da pesquisa foi construir um instrumento para realização de screening em alunos de escolas da educação básica. Para isso, valeu-se do método psicofísico de comparação por pares, por meio de pesquisa de campo. A análise dos dados pautou-se na estatística não-paramétrica e análise fatorial exploratória. Concluiu-se que houve indicativos da capacidade
\end{abstract}

\footnotetext{
1 Fabiana Oliveira Koga possui graduação em instrumento piano e em Educação Musical pela Universidade do Sagrado Coração, Bauru/SP. Pós-Graduada em Psicopedagogia clínica pela Faculdade Paulista, é Mestre e doutora em Educação pela Universidade Estadual Paulista - Faculdade de Filosofia e Ciências, campus de Marília. Durante o mestrado foi bolsista CNPq e, durante o doutorado, foi bolsista da Fundação de Amparo à Pesquisa do Estado de São Paulo (FAPESP). É autora do livro "Precocidade e Superdotação Musical" e autora, com o apoio da FAPESP, do "Protocolo para Screening de Habilidades Musicais". Participou do projeto de extensão Programa de Atenção ao aluno Precoce com comportamento de Superdotado (PAPCS) e foi membro do Grupo de Pesquisa Educação e Saúde de Grupos Especiais em parceria com a Faculdade de Medicina de Marília (FAMEMA). Em 2017 participou do curso de formação com Joseph S. Renzulli na Universidade de Connecticut. Foi membro do grupo de pesquisa Diferença, Desvio e Estigma sob a coordenação do Professor Dr. Sadao Omote da Faculdade de Filosofia e Ciências, UNESP e, atualmente, é membro do Grupo de Pesquisa para o Desenvolvimento do Potencial Humano (GRUPOH).

2 Possui graduação em Pedagogia pela Universidade de Guarulhos (2002), graduação em Direito - Faculdades Integradas de Guarulhos (1982), mestrado em Educação - Universidade Cidade de São Paulo (2005) e doutorado em Educação Especial Universidade Federal de São Carlos (2012). Atualmente é professora adjunto 4 da Universidade Federal de São Carlos. Tem experiência na área de Educação, com ênfase em Educação Especial, atuando principalmente nos seguintes temas: altas habilidades/superdotação, atendimento educacional especializado, gestão educacional e surdocegueira. É lider do Grupo de Pesquisa para o Desenvolvimento do Potencial Humano (GRUPOH) (UFSCar) e vice lider do Grupo de Pesquisa Excelência, Sustentabilidade e Inovação Social: Engenharia das Organizações Criativas e Soluções Tecnológicas Educacionais (UNIRIO). Coordenadora do Laboratório de Pesquisa de Altas Habilidades (LAPAH). Membro da Red Internacional de Investigación, Intervención y Evaluaciónen Altas Capacidades Intelectuales (REINEVA). Membro da Comissão Técnica do Conselho Brasileiro para Superdotação (ConBraSD).
} 
de mensuração do instrumento, porém será preciso continuar os procedimentos de validação e fidedignidade.

Palavras-chave: Educação Musical. Talento musical. Identificação. Screening.

Abstract: Musical talent can be found in different persons, from different social and economic conditions and phases of life. Legislation guarantees identification, registry and special educational service for the talent students. This study aimed at developing an instrument in order to carry on a screening process in Basic Education students. In order to do so, it was valued the peer comparison psychophysical method, as well as a field research. The data analysis was conducted by means of the nonparametric statistics and exploratory factor analysis. In conclusion, there were indications of measuring potential of the instrument however, it will be necessary to carry on the validation and reliability procedures.

Keywords: Musical Education. Musical Talent. Identification. Screening. 


\section{Introdução}

Indivíduos com talento são considerados pela legislação brasileira, ${ }^{1}$ Lei n. 9.394, como parte do público que integra a Educação Especial (BRASIL, 1996). A Lei no 13.234 orienta a identificação precoce dos estudantes talentosos, seu cadastramento e o direito ao atendimento educacional especializado, bem como execução de políticas públicas (BRASIL, 2015).

O talento pode se manifestar em diferentes pessoas, em qualquer etapa da vida, em todas as classes sociais e áreas do conhecimento humano como, por exemplo, na área da música. Então, o que constitui o talento musical? Que fenômeno é esse?

Kirnarskaya $(2004,2013)$ discute que pessoas talentosas manifestam a habilidade para apreciar e aprender elementos musicais. Além disso, elas se envolvem e se dedicam com afinco, buscando internalizar a música; também são criativas e motivadas por novas experimentações e perspectivas. A Figura 1 é um esboço da síntese elaborada pela autora a respeito da estrutura do talento musical.

Figura 1 - Termos básicos do conceito de talento

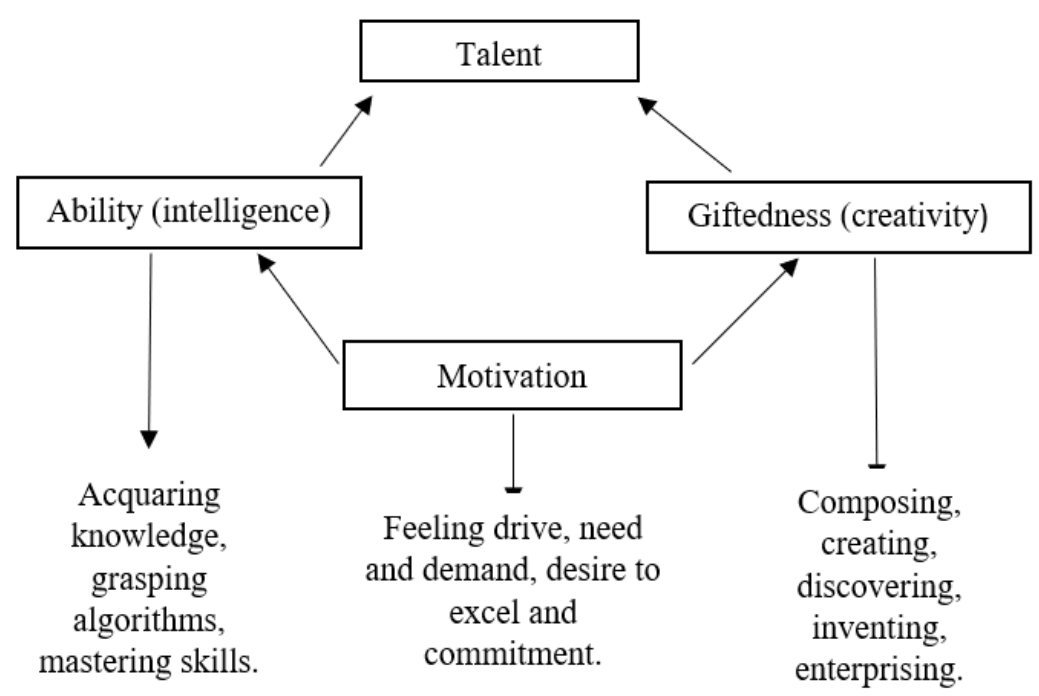


Evidências preliminares de talento musical em crianças na educação básica Fabiana Oliveira Koga • Rosemeire de Arauljo Rangni

"O talento se caracteriza pela aptidão de produzir grandes coisas, mas as quais se mantêm dentro de um marco do que foi alcançado até então" (RUBINSTEIN, 1967, p. 711, tradução nossa). ${ }^{2}$ A personalidade, a autonomia para educar-se, a internalização rápida dos elementos e o trabalho são fatores que contribuem para a manifestação e desenvolvimento do talento, reitera Rubinstein (1967).

Teplov (1966) discute que os fatores que compõem o talento musical são: sensibilidade para discernir sons e ritmos; imaginação/ criatividade; memória musical e afetividade pela área. Para o autor, o talento se conecta com a intuição, a coragem, a motivação, a perseverança e a paciência. A personalidade seria um importante fator na determinação do plano de carreira e na constituição da identidade do sujeito talentoso.

Já Haroutounian (2002) assinala que a manifestação do talento ocorre a partir de um spark (fagulha ou centelha) ${ }^{3}$ que se "acende" internamente quando a pessoa talentosa vivencia ou se emerge na área da música.

Como o talento musical, cientificamente, qualifica-se como constructo, ele foi foco de mensuração de pesquisadores de diferentes realidades educacionais e culturais, como é possível verificar a partir das pesquisas de Seashore (1938), Gordon (2000) e Haroutounian (2002), entre outros. Há também autores que incluíram a identificação musical em suas pesquisas devido à amplitude que buscavam nos rastreios realizados, tais quais: Renzulli e Reis (2014), Gagné e Guenther (2012) e Freitas e Pérez (2012), para citar alguns.

No entanto, o fato de não haver um instrumento de mensuração específico da área e validado para a realidade cultural, a qual se propõe avaliar, torna-se complexo garantir que os resultados alcançados por esses instrumentos sejam completamente fidedignos. No Brasil, há muitos instrumentos ainda sem validade, o que dificulta a identificação correta e o encaminhamento. Essa problemática foi discutida por Farias e Wechsler (2014). 
Evidências preliminares de talento musical em crianças na educação básica Fabiana Oliveira Koga • Rosemeire de Arauljo Rangni

A partir dessa contextualização, o Protocolo para Screening de Habilidades Musicais (PSHM) foi pensado por Koga (2019). O PSHM conta com 127 itens distribuídos e agrupados em oito dimensões. Durante cada uma das dimensões há faixas-treino orientando os participantes ao longo da execução dos exercícios propostos, isso porque o PSHM pode ser aplicado em participantes sem experiência musical. O Quadro 1 expõe as dimensões e itens desse protocolo.

Quadro 1 - Estrutura do PSHM em dimensões e itens

\begin{tabular}{|c|c|c|}
\hline HABILIDADES & DIMENSÕES & ITENS \\
\hline \multirow{4}{*}{$\begin{array}{c}\text { Sensório-percep- } \\
\text { tivas }\end{array}$} & Timbre & 15 pares de A a O \\
\cline { 2 - 3 } & Altura & 18 pares de A a R \\
\cline { 2 - 3 } & Melodia & 14 pares de A a N \\
\cline { 2 - 3 } & Intensidade & 11 pares de A a K \\
\cline { 2 - 3 } Rítmicas & Harmonia & 20 pares de A a T \\
\hline \multirow{3}{*}{} & Duração & 16 pares de A a P \\
\cline { 2 - 3 } & Padrão-rítmico & 19 pares de A a S \\
\cline { 2 - 3 } & Agógica & 14 pares de A a N \\
\hline
\end{tabular}

Fonte: elaborado pelas autoras

Os itens foram organizados em pares porque o Método Psicofísico de Comparação por Pares, em que se baseou a construção do protocolo, exige que se apresente "[...] ao sujeito dois estímulos simultaneamente. Ele deve julgar qual dos dois estímulos em uma quantidade maior da qualidade que está sendo julgada" (MANNING, 1974, p. 80). No PSHM, os participantes julgarão se os sons e ritmos ouvidos foram diferentes ou iguais, conforme a sua percepção. Como também se cuidou das questões sonoras e rítmicas culturais (ROEDERER, 2002; SLOBODA, 2008; PASQUALI, 2013), o PSHM foi submetido à análise semântica com a colaboração e julgamento de profissionais da área da Música, tendo sido realizadas testagens piloto e preliminares do referido protocolo como se pode encontrar descrito em Koga (2019) para equalizar os áudios e corrigir as possíveis fragilidades do material. 
Evidências preliminares de talento musical em crianças na educação básica Fabiana Oliveira Koga • Rosemeire de Arauljo Rangni

A Figura 2 contempla a estrutura do PSHM para realização de screening quando foi criado.

Figura 2 - Estrutura do PSHM quanto ao processo de construção

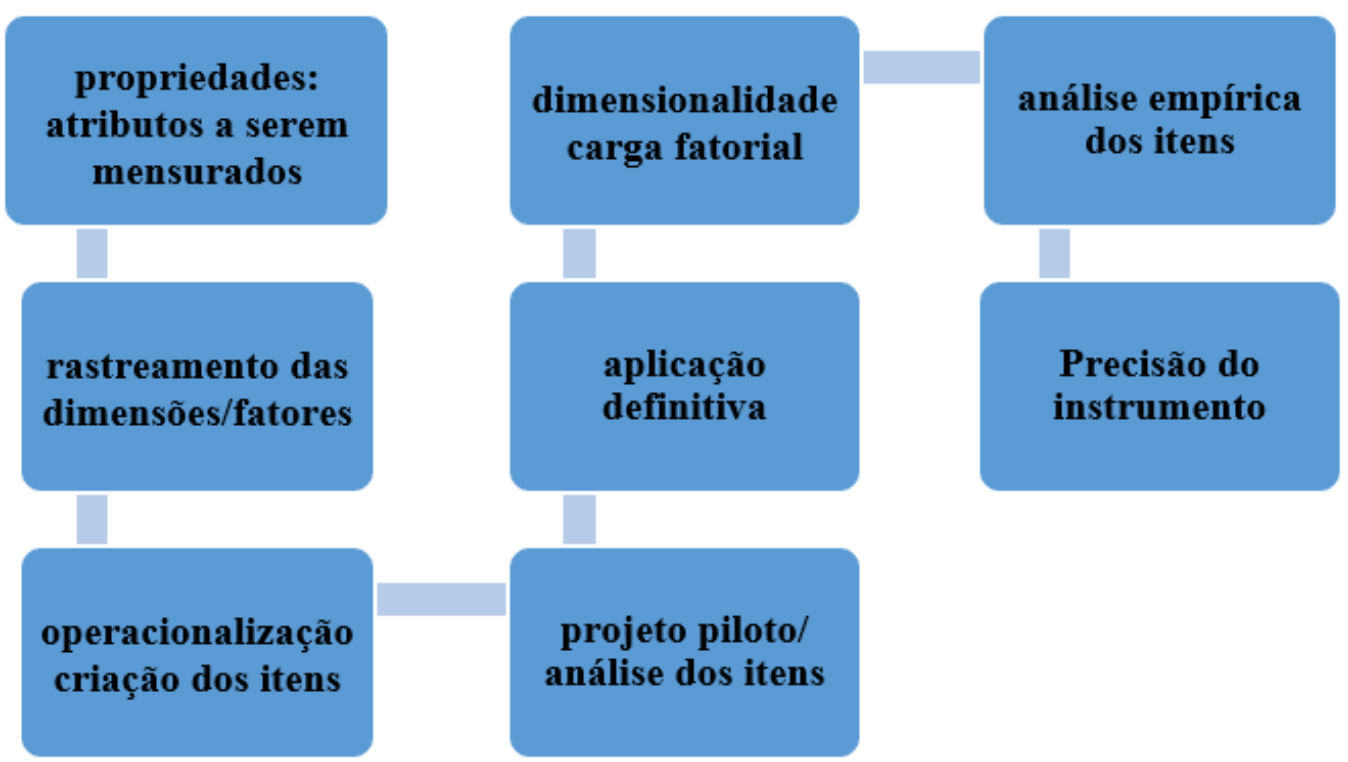

Fonte: elaborado pelas autoras

O PSHM foi construído na técnica para screening com base na realidade das escolas de educação básica. A maioria delas não conta com espaços e ambientes para atividades extras; por vezes, a matriz curricular não contempla horas remanescentes e também não se conta com educadores musicais, mesmo diante da obrigatoriedade preconizada na Lei $n^{\circ} 13.278 / 16$, a qual altera o §6o do art. 26 da Lei no 9.394/96 (BRASIL, 2016). Além disso, há que se considerar a sobrecarga da jornada de trabalho dos professores. Portanto, optou-se pela seleção da rota auditiva, aplicação em massa, fácil usabilidade e tabulação simples e subjetividade controlada.

Essa estrutura pautou-se nas pesquisas de Borland e Wright (2004), as quais argumentam que o screening é um processo de identificação ou rastreamento e não se condiciona a um especialista da área de Música para a aplicação. 
Evidências preliminares de talento musical em crianças na educação básica Fabiana Oliveira Koga • Rosemeire de Arauljo Rangni

A fase seguinte ao processo de screening - a avaliação exige um especialista com formação na área do talento. Renzulli (2014) postula que 15\% dos estudantes necessitam de serviços suplementares e Benito (2003) assinala que 10\% de estudantes com indícios de talento poderão se sobressair em procedimentos de screening.

Caso a Educação Musical fosse uma realidade em todas as escolas brasileiras, se os professores de Música fossem formados em Educação Especial e com formação específica para o talento, muitos estudantes não estariam sendo negligenciados e privados de seu desenvolvimento musical.

Sendo assim, o PSHM foi criado a partir do seguinte questionamento: um instrumento para screening baseado no Método Psicofísico de Comparação por Pares, exclusivo para a mensuração do talento musical, de modo inicial, seria sensível no rastreamento de crianças com indícios de talento musical? Diante do exposto, o objetivo da pesquisa foi construir o PSHM para realização de screening em alunos de escolas de educação básica.

Ressalta-se que o PSHM não mensura o talento musical em sua completude, apenas preliminarmente via acuidade auditiva. Por essa razão é um instrumento de sondagem ou identificação inicial, necessitando de etapas avaliativas posteriores caso haja pessoas indicadas preliminarmente pelo PSHM.

\section{Método}

O estudo caracteriza-se como pesquisa de campo atrelada à construção de uma escala padronizada nos moldes psicofísicos (MANNING, 1974; SEVERINO, 2007; PASQUALI, 2013).

A Psicofísica é um segmento que estuda a relação de um estímulo físico dado em relação às características psicológicas envolvidas em sua compreensão pelo sujeito. De acordo com Manning (1974), quando o sujeito responde a um estímulo sonoro, 
Evidências preliminares de talento musical em crianças na educação básica Fabiana Oliveira Koga • Rosemeire de Arauljo Rangni

torna-se possível inferir se ele percebeu o estímulo e como o apreendeu e, assim, a Psicofísica opera em âmbito de previsão, apresentando limiares estatísticos aproximados e não absolutos. A Psicofísica se ocupa do estudo de fenômenos como as sensações, percepção e cognição (FEITOSA, 2010). Com relação à pesquisa de campo, Severino (2007, p. 123) argumenta que "[...] o objeto/fonte é abordado em seu meio ambiente próprio. A coleta dos dados é feita nas condições naturais em que os fenômenos ocorrem, sendo assim diretamente observados, sem intervenção e manuseio por parte do pesquisador".

A Figura 3 ilustra o processo para screening proposto, utilizando o PSHM como uma das etapas.

Figura 3 - Processo de identificação por screening com o PSHM

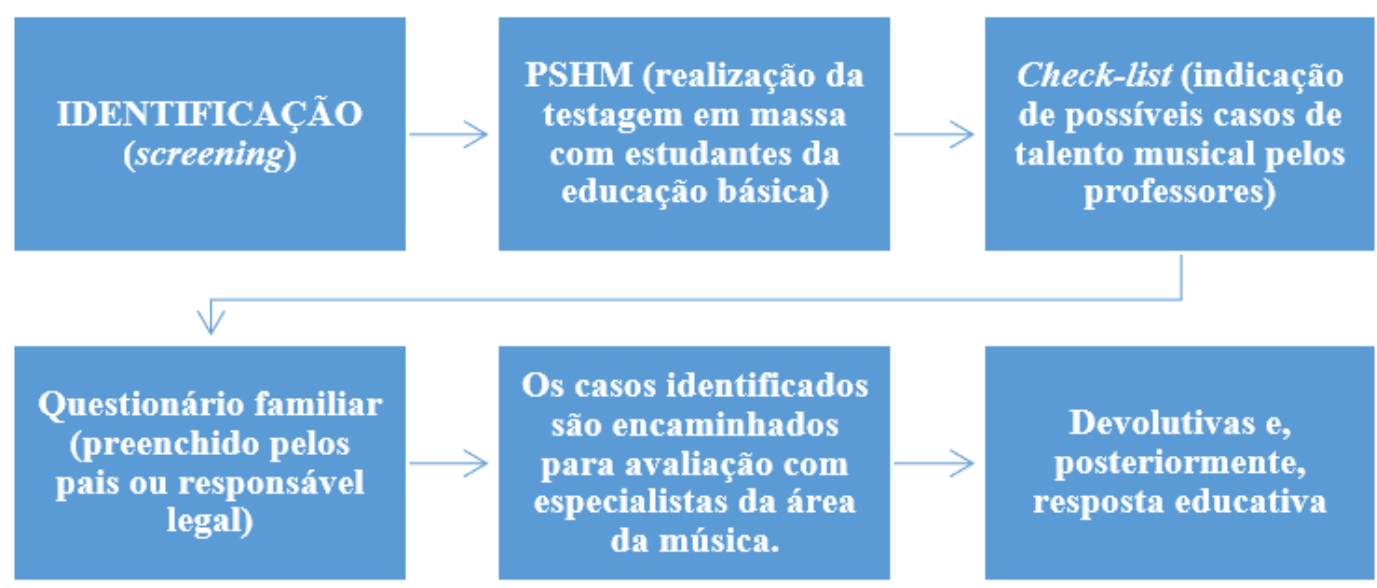

Fonte: elaborado pelas autoras

O PSHM conta com um material físico e virtual e instruções padronizadas mediante manual. A diferença entre as versões ocorre na forma do preenchimento e no momento da tabulação: no material físico ela é manual e no ambiente virtual ela é realizada automaticamente. Os exercícios são rigorosamente iguais bem como os comandos. Sua duração é de aproximadamente uma hora e o citado protocolo conta com algumas adaptações para pessoas com deficiência. 
Evidências preliminares de talento musical em crianças na educação básica Fabiana Oliveira Koga • Rosemeire de Arauljo Rangni

Participaram das etapas de elaboração do PSHM 653 estudantes do sexo masculino e feminino, com idades entre seis e onze anos, matriculados nos anos iniciais do Ensino Fundamental de escolas públicas e privadas, com e sem o educador musical. É preciso destacar que os 653 participantes foram distribuídos entre projeto piloto, análise semântica, etapas de construção da plataforma, aplicação pareada (versão impressa versus virtual) e aplicação definitiva do protocolo. Os participantes não se repetiram nas etapas.

O PSHM foi aplicado em salas de aula regulares e nos laboratórios de informática das escolas participantes. Todos os estudantes utilizaram fones de ouvido externos com protetores para manutenção da higiene, tanto na versão impressa quanto virtual do PSHM.

Preliminarmente realizou-se o projeto piloto com um menino e uma menina do $1^{\circ}$ ao $5^{\circ}$ ano, de escola pública e de particular. Os resultados foram analisados e procederam-se os ajustes necessários para, posteriormente, ocorrer a aplicação com os demais participantes.

Vale mencionar que todas as providências éticas foram asseguradas mediante aprovação CAAE: 52337415.9.00005406. Além disso, todas as escolas participantes bem como os responsáveis legais pelos estudantes assinaram os respectivos termos de consentimento. No presente texto, serão tratados os dados referentes exclusivamente à construção do PSHM.

Com relação à análise dos dados, ${ }^{4}$ cada resultado passou por tabulação e foi convertido em escore: o numeral "1" representou o acerto e "0" o erro em cada item. Em seguida, foram analisados os índices de respostas aleatórias, a capacidade de mensuração de cada item por meio do teste estatístico qui-quadrado (X2) e $W$ de Kendell e, também, averiguou-se a confiabilidade interna dos itens do PSHM mediante Alfa de Cronbach (PASQUALI, 2010, 2013).

Como o PSHM conta com duas versões, virtual e manual, aplicouse o teste estatístico Wilcoxon e o teste estatístico Mann - Whitney 
Evidências preliminares de talento musical em crianças na educação básica Fabiana Oliveira Koga • Rosemeire de Arauljo Rangni

para averiguar se haveria diferenças significativas, conforme Field (2009) e Bruni (2011), entre a escola pública e a particular devido à presença do especialista da área da Música na rede privada. Por fim, para analisar a correlação entre as dimensões, aplicou-se a análise fatorial exploratória (FIELD, 2009). Por ser uma escala para screening voltada para a área da Educação e da Música, o PSHM passou por procedimentos estáticos não paramétricos, porque não compara parâmetros, e hipóteses são formuladas, pois não demandam que a variável em análise seja numérica, o que torna possível aplicá-lo a hábitos, comportamentos, preferências, intensidades, entre outros (VIEIRA, 2018).

Uma máscara de correção foi utilizada para mensurar os resultados das folhas de respostas impressas. A tabulação na plataforma ocorreu automaticamente. Atribuiu-se "0" para os erros e "1" para os acertos. Um banco de dados foi composto para registrar o participante e seus resultados em ambas as versões.

\section{Resultados e discussão}

Com os resultados ordenados no banco de dados, aplicou-se o teste estatístico binomial para averiguar índices de respostas aleatórias. Com os resultados, foi possível averiguar discrepâncias nos seguintes itens das dimensões: 
Evidências preliminares de talento musical em crianças na educação básica Fabiana Oliveira Koga • Rosemeire de Arauljo Rangni

Tabela 1 - Resultados das escolas públicas e privadas no teste estatístico binomial

\begin{tabular}{c|c}
\hline Dimensões & Itens discrepantes $(\mathbf{p = 0 , 0 5})$ \\
\hline Timbre & 2 \\
Altura & 9 \\
Melodia & 3 \\
Intensidade & 4 \\
Harmonia & 7 \\
Agógica & 9 \\
Duração & 9 \\
Padrão-rítmico & 11 \\
\hline Total $(\mathrm{n}=127)$ & 54 \\
\hline
\end{tabular}

Fonte: elaborado pelas autoras

Os itens indicados na Tabela 1 permitem inferir que estão iguais ou inferiores a $p=0,05$, além disso, há itens superiores, 0 que gera a necessidade de revisão ou rejeição deles. Esses itens apresentaram alguma facilidade ou dificuldade exacerbada para os participantes, por isso os baixos índices estatísticos. Para Pasquali $(2010,2013)$, um item difícil pode afetar a resposta do participante. Além disso, o participante pode responder ao instrumento com má disposição, em tom de brincadeira e outros comportamentos que invalidam sua resposta. Ainda, o item pode se apresentar fácil demais, ocasionando o acerto em massa dele.

Os resultados no teste estatístico Qui-Quadrado $\left(X^{2}\right)$ permitiram encontrar, em sua maioria, itens com mensuração significativa em decorrência de apresentarem $p<0,05$, mas também itens com variáveis constantes, as quais indicaram que os participantes os gabaritaram. Esses resultados permitiram concluir que será necessário rever os itens com variáveis constantes conforme as séries. Como alguns itens aparecem como variável constante em uma série e em outra não, observou-se a necessidade de haver diferentes versões para o PSHM. Essa afirmação se confirmou no teste de confiabilidade Alfa de Cronbach, conforme Tabela 2. 
Evidências preliminares de talento musical em crianças na educação básica Fabiana Oliveira Koga • Rosemeire de Arauljo Rangni

Tabela 2 - Resultados do teste de confiabilidade Alfa de Cronbach

\begin{tabular}{|c|c|c|c|c|c|}
\hline \multicolumn{6}{|c|}{ REDE PÚBLICA } \\
\hline ITENS & $1^{\circ}(N=51)$ & $2^{\circ}(N=45)$ & $3^{\circ}(\mathrm{N}=61)$ & $4^{\circ}(N=38)$ & $5^{\circ}(N=32)$ \\
\hline TIMBRE N=15 & 0,687 & 0,757 & 0,713 & 0,060 & 0,591 \\
\hline ALTURA N=18 & 0,562 & 0,592 & 0,614 & 0,688 & 0,792 \\
\hline MELODIA N=14 & 0,039 & 0,243 & 0,412 & 0,096 & 0,460 \\
\hline INTENSIDADE N=11 & 0,378 & 0,465 & 0,640 & 0,428 & 0,571 \\
\hline HARMONIA N=20 & 0,113 & 0,465 & 0,540 & 0,582 & 0,645 \\
\hline AGÓGICA N=14 & 0,135 & 0,369 & 0,513 & 0,394 & 0,470 \\
\hline DURAÇÃO N=16 & 0,766 & 0,759 & 0,730 & 0,583 & 0,728 \\
\hline $\begin{array}{l}\text { PADRÃO RÍTMICO } \\
\mathrm{N}=19\end{array}$ & 0,284 & 0,413 & 0,528 & 0,673 & 0,565 \\
\hline ITENS & $1^{\circ}(\mathrm{N}=\mathbf{2 2})$ & $2^{\circ}(N=34)$ & $3^{\circ}(\mathrm{N}=37)$ & $4^{\circ}(N=30)$ & $5^{\circ}(\mathrm{N}=32)$ \\
\hline TIMBRE N=15 & 0,225 & 0,495 & 0,650 & 0,463 & $-0,281$ \\
\hline ALTURA N=18 & 0,591 & 0,715 & 0,731 & 0,769 & 0,577 \\
\hline MELODIA N=14 & 0,394 & 0,244 & 0,384 & 0,608 & 0,535 \\
\hline INTENSIDADE N=11 & 0,616 & 0,574 & 0,584 & 0,668 & 0,245 \\
\hline HARMONIA N=20 & 0,419 & 0,553 & 0,513 & 0,536 & 0,679 \\
\hline AGÓGICA N=14 & 0,338 & 0,432 & 0,689 & 0,659 & 0,175 \\
\hline DURAÇÃO N=16 & 0,418 & 0,689 & 0,465 & 0,717 & 0,175 \\
\hline $\begin{array}{l}\text { PADRÃO RÍTMICO } \\
\mathrm{N}=19\end{array}$ & 0,177 & 0,351 & 0,638 & 0,560 & 0,326 \\
\hline
\end{tabular}

Fonte: elaborado pelas autoras

Ao analisar os resultados, observou-se que as crianças menores apresentam um pouco mais de dificuldade na expressão de sua resposta. Feitosa (2010) já havia constatado o mesmo em suas pesquisas. Para a autora, as crianças, principalmente as menores, expressam suas respostas impulsivamente em atividades dessa natureza. As mais velhas conseguem apreender o estímulo, pensam sobre ele e depois emitem sua resposta, mas não se trata de uma regra porque há um valor negativo de $p=-0,281$ na dimensão timbre para o $5^{\circ}$ ano, indicando uma possível dificuldade para iniciar o PSHM. Na Tabela 3 observam-se os resultados do coeficiente de concordância. 
Evidências preliminares de talento musical em crianças na educação básica Fabiana Oliveira Koga • Rosemeire de Arauljo Rangni

Tabela 3 - Resultados do coeficiente de concordância de W de Kendell

\begin{tabular}{ccccc}
\hline Rede & Ano & Total de participantes & \multicolumn{2}{c}{ W de Kendell } \\
& $1^{\circ}$ & 51 & 0,361 & $\mathrm{p}=0,000$ \\
& $2^{\circ}$ & 45 & 0,427 & $\mathrm{p}=0,000$ \\
Pública & $3^{\circ}$ & 61 & 0,518 & $\mathrm{p}=0,000$ \\
& $4^{\circ}$ & 38 & 0,639 & $\mathrm{p}=0,000$ \\
& $5^{\circ}$ & 32 & 0,617 & $\mathrm{p}=0,000$ \\
& $1^{\circ}$ & 22 & 0,556 & $\mathrm{p}=0,000$ \\
Particu- & $2^{\circ}$ & 34 & 0,543 & $\mathrm{p}=0,000$ \\
lar & $3^{\circ}$ & 37 & 0,590 & $\mathrm{p}=0,000$ \\
& $4^{\circ}$ & 30 & 0,632 & $\mathrm{p}=0,000$ \\
& $5^{\circ}$ & 32 & 0,710 & $\mathrm{p}=0,000$ \\
\hline
\end{tabular}

Fonte: elaborado pelos autoras

A partir desses resultados, foi possível concluir que há correlação significativa entre as dimensões pois $p<0,05$, conforme orienta Field (2009).

O PSHM foi aplicado de modo pareado em uma das escolas participantes.5 Foi realizada a aplicação impressa primeiramente e, após intervalo de 60 dias, realizou-se a aplicação do PSHM virtual. Mediante o teste estatístico de Wilcoxon, concluiu-se que o $1^{\circ}$ ano obteve $p=0,0625$, diferença estatisticamente não significante; 0 $2^{\circ}$ ano obteve resultado de $p=0,0049$, considerada uma diferença estatisticamente muito significante; $03^{\circ}$ ano obteve $p=0,0479$, diferença significativa; o $4^{\circ}$ ano obteve $p=0,0020$, diferença muito significativa; e $05^{\circ}$ ano obteve $p=0,0020$, considerada muito significante. A Tabela 4 contempla o desempenho dos participantes com base na distribuição. 
Evidências preliminares de talento musical em crianças na educação básica Fabiana Oliveira Koga • Rosemeire de Arauljo Rangni

Tabela 4 - Valores de Distribuiç̧̃es

\begin{tabular}{ccccc}
\hline $\begin{array}{c}\text { Ano/n. de } \\
\text { participan- } \\
\text { tes }\end{array}$ & $\begin{array}{c}\text { PSHM/aplica- } \\
\text { ção }\end{array}$ & $\begin{array}{c}\text { Variação } \\
\text { (Min-Máx) }\end{array}$ & $\begin{array}{c}\text { Media- } \\
\text { na }\end{array}$ & $\begin{array}{c}\text { Dispersão } \\
\text { (Q1 - Q3) }\end{array}$ \\
\hline \multirow{2}{*}{$1(n=06)$} & impressa & $58-95$ & 75 & $69-78$ \\
& plataforma & $40-97$ & 52,5 & $44,75-59,5$ \\
$2(n=11)$ & impressa & $48-94$ & 81 & $77-91$ \\
& plataforma & $36-85$ & 52 & $45-64$ \\
$3(n=13)$ & impressa & $64-98$ & 81 & $72-86$ \\
& plataforma & $42-90$ & 74 & $69-79$ \\
$4(n=11)$ & impressa & $74-101$ & 87 & $82,50-91,50$ \\
& plataforma & $70-96$ & 79 & $75-85$ \\
$5(n=10)$ & impressa & $65-108$ & 86,5 & $82,50-96,50$ \\
& plataforma & $52-88$ & 71,5 & $66,25-79,75$ \\
\hline Total & & $36-108$ & 73,95 & $68,30-81,02$ \\
\hline
\end{tabular}

Fonte: elaborado pelas autoras

Os resultados expuseram que, do $2^{\circ}$ ao $5^{\circ}$ ano, há diferenças significativas na realização do PSHM impresso e virtual. Com relação ao $1^{\circ}$ ano, essa diferença não se apresenta significativa.

Ao realizar a análise fatorial exploratória, na rotação varimax com normatização de Kayser e com valor de eigenvalues, a rede pública obteve, no fator 1, 37,06\%; no fator $2,16,28 \%$ e no fator $3,13,66 \%$. Diante disso, no fator 1 , agógica $(0,86)$, duração $(0,84)$ e padrão-rítmico $(0,74)$ se correlacionaram; no fator 2 , timbre $(0,90)$, intensidade $(0,70)$ e altura $(0,64)$; e no fator 3 , melodia $(0,78)$ e harmonia $(0,77)$ estão correlacionadas. No $1^{\circ}$ ano da escola particular, os valores de eigenvalues foram: no fator 1, 40,68\%; no fator $2,17,86 \%$ e no fator $3,14,73 \%$. Se correlacionaram, no fator 1 , agógica $(0,91)$, harmonia $(0,85)$ e altura $(0,53)$; no fator 2 , padrãorítmico $(0,82)$, duração $(0,79)$ e melodia $(0,67)$; e no fator 3 , timbre $(0,87)$ e intensidade $(0,78)$.

No $2^{\circ}$ ano da escola pública, foi realizada a mesma rotação varimax com normatização de Kayser e os valores de eigenvalues. No fator 1 o valor obtido foi $42,40 \%$ e, no fator 2 , de $14,07 \%$. 
Evidências preliminares de talento musical em crianças na educação básica Fabiana Oliveira Koga • Rosemeire de Arauljo Rangni

Sendo assim, o fator 1 correlacionou timbre $(0,79)$, intensidade $(0,71)$ e duração $(0,60)$, e o fator 2 , padrão-rítmico e melodia $(0,75)$, harmonia $(0,62)$, altura $(0,57)$ e agógica $(0,49)$. Os resultados da escola particular, nas mesmas condições de análise, apresentaram: no fator $1,39,93 \%$ e, no fator $2,13,49 \%$. No fator 1 , a correlação se deu entre padrão-rítmico $(0,70)$, harmonia $(0,62)$, melodia $(0,52)$, duração $(0,48)$ e timbre $(0,44)$. No fator 2 , intensidade $(0,85)$, altura $(0,47)$ e agógica $(0,37)$.

No $3^{\circ}$ ano da rede pública, a análise fatorial exploratória, na rotação varimax, permitiu encontrar valores de eigenvalues de $35,54 \%$, no fator 1 , e $19,32 \%$, no fator 2 . No fator 1 , a correlação se deu entre duração $(0,88)$, padrão-rítmico $(0,80)$, agógica $(0,53)$, intensidade $(0,81)$ e timbre $(0,41)$. No fator 2 foram melodia $(0,80)$, altura $(0,73)$ e harmonia $(0,61)$. Na rede particular, nas mesmas condições de análise, os resultados foram, nos valores de eigenvalues: fator 1, 25,61\%; fator 2, 20,44\%; no fator 3, 16,05\%, e no fator 4, 13,83\%. Em termos de correlação, no fator 1, duração $(0,85)$ e padrão-rítmico $(0,87)$; no fator 2 , melodia $(0,92)$ e agógica $(0,50)$; no fator 3 , timbre $(0,87)$ e harmonia $(0,63)$ e, no fator 4 , intensidade $(0,89)$ e altura $(0,68)$.

Os resultados do $4^{\circ}$ ano na rede pública, na rotação varimax, apresentaram os valores de eigenvalues de $35,65 \%$ no fator 1 , $17,02 \%$, no fator 2 e $13,79 \%$ no fator 3 . O fator 1 é composto por agógica $(0,88)$, padrão-rítmico $(0,82)$, harmonia $(0,66)$ e duração $(0,79)$. O fator 2 é composto por altura $(0,83)$ e melodia $(0,75)$, e o fator 3 é composto por timbre $(0,89)$ e intensidade $(0,51)$. Na rede particular, os valores de eigenvalues foram $38,86 \%$ no fator $1 ; 14,74 \%$ no fator 2 , e $12,78 \%$ no fator 3 . A correlação que se estabeleceu no fator 1 foi timbre $(0,87)$, padrão-rítmico $(0,66)$ e duração $(0,58)$. No fator 2 , melodia $(0,87)$ e harmonia $(0,64)$ e, no fator 3 , intensidade $(0,84)$, agógica $(0,74)$ e altura $(0,53)$.

Os resultados do $5^{\circ}$ ano da rede pública, nas mesmas condições de análise, possibilitaram acessar os valores de eigenvalues de $50,92 \%$ no fator 1 , e $17,98 \%$ no fator 2 . A correlação obtida no fator 1 foi de melodia $(0,84)$, altura $(0,83)$, harmonia $(0,80)$, intensidade 
Evidências preliminares de talento musical em crianças na educação básica Fabiana Oliveira Koga • Rosemeire de Arauljo Rangni

$(0,63)$ e agógica $(0,72)$ e, no fator 2 , timbre $(0,84)$, duração $(0,70)$ e padrão-rítmico $(0,69)$. Os valores de eigenvalues, na rede particular, foram de $30,28 \%$ no fator $1 ; 17,96 \%$ no fator 2 , e $15,61 \%$ no fator 3 . A correlação estabelecida no fator 1 foi entre as dimensões altura $(0,83)$, agógica $(0,82)$, melodia $(0,66)$ e duração $(0,65)$. No fator 2 , foi entre padrão-rítmico $(0,79)$ e intensidade $(0,62)$ e, no fator 3 , harmonia $(0,82)$ e timbre $(0,63)$.

Os valores obtidos mediante a correlação permitem concluir que as dimensões podem compor similar testagem e indicam características do mesmo fenômeno. Esse tipo de correlação é encontrado em instrumentos padronizados similares, como os de Seashore (1938) e Gordon (2000).

Ao comparar escola pública versus particular no teste estatístico Mann-Whitney, obteve-se $p=0,0479$, considerado estatisticamente significante para os $1^{\circ}$ anos; $p=0,0031$, considerado muito significante para os $2^{\circ}$ anos; $p=0,0001$, considerado extremamente significante para os $3^{\circ}$ anos; $p=0,0487$, considerado significante para os $4^{\circ}$ anos, e $p=0,0040$, considerado muito significante para os $5^{\circ}$ anos.

Tabela 4 - Valores de Distribuições

\begin{tabular}{|c|c|c|c|c|}
\hline Ano & Rede & $\begin{array}{l}\text { Variação } \\
\text { (Min-Máx) }\end{array}$ & Mediana & $\begin{array}{c}\text { Dispersão } \\
\text { (Q1 - Q3) }\end{array}$ \\
\hline \multirow[b]{2}{*}{1} & Pública ( $n=51)$ & $48-97$ & 67 & $63-76$ \\
\hline & $\begin{array}{l}\text { Particular } \\
\quad(n=22)\end{array}$ & $55-101$ & 75,50 & $69-81,50$ \\
\hline \multirow[b]{2}{*}{2} & Pública (n=45) & $49-111$ & 77 & $68-87$ \\
\hline & $\begin{array}{l}\text { Particular } \\
\quad(n=34)\end{array}$ & $62-108$ & 86,50 & $79,25-93,50$ \\
\hline \multirow[b]{2}{*}{3} & Pública (n=61) & $61-107$ & 87 & $80-94$ \\
\hline & $\begin{array}{l}\text { Particular } \\
\quad(n=37)\end{array}$ & $82-114$ & 98 & $94-104$ \\
\hline \multirow[b]{2}{*}{4} & Pública (n=38) & $76-110$ & 92,50 & $86-102$ \\
\hline & $\begin{array}{l}\text { Particular } \\
(n=30)\end{array}$ & $71-117$ & 99,50 & $93-106,25$ \\
\hline
\end{tabular}


Evidências preliminares de talento musical em crianças na educação básica Fabiana Oliveira Koga • Rosemeire de Arauljo Rangni

\begin{tabular}{ccccc} 
& Pública $(\mathrm{n}=32)$ & $70-113$ & 90 & $82,75-103,75$ \\
5 & $\begin{array}{c}\text { Particular } \\
(\mathrm{n}=32)\end{array}$ & $90-120$ & 102 & $97-106,25$ \\
\cline { 1 - 2 } & $\mathrm{n}=382$ & $48-120$ & 87,50 & $81,20-95,42$ \\
\hline Total & & & & \\
\hline
\end{tabular}

Fonte: elaborado pelas autoras

Os dados anteriores remetem, principalmente por conta dos valores de distribuição na Tabela 5, que as escolas da rede particular são superiores às da rede pública no desempenho no PSHM. No entanto, é preciso destacar que essa diferença pode estar justificada pela presença dos professores especialistas em música que lecionam semanalmente a disciplina de Educação Musical. O estudo intensivo e sistemático de música pode contribuir com o desempenho musical. Isso pode ser comprovado a partir de pesquisa realizada por Koga e Chacon (2017).

Outra análise realizada utilizando o teste estatístico KruskallWallis foi/considerou anos escolares versus anos escolares. $\mathrm{Na}$ rede pública, obteve-se $p<0,0001$, considerado extremamente significante, e na rede particular $p<0,0001$, também extremamente significante.

Tabela 5 - Resultado das distribuições

\begin{tabular}{|c|c|c|c|c|}
\hline Rede & Ano/participantes & $\begin{array}{l}\text { Variação } \\
\text { (Min-Máx) }\end{array}$ & Mediana & $\begin{array}{c}\text { Dispersão } \\
\text { (Q1 - Q3) }\end{array}$ \\
\hline \multirow{5}{*}{$\frac{\frac{0}{0}}{\frac{0}{0}}$} & $1(n=51)$ & $48-97$ & 67 & $63-76$ \\
\hline & $2(n=45)$ & $49-111$ & 77 & $68-87$ \\
\hline & $3(n=61)$ & $61-107$ & 87 & $80-94$ \\
\hline & $4(n=38)$ & $76-110$ & 92,50 & $86-102$ \\
\hline & $5(n=32)$ & $70-113$ & 90 & $82,75-103,75$ \\
\hline \multirow{5}{*}{ 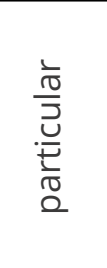 } & $1(n=22)$ & $55-101$ & 75,50 & $69-81,50$ \\
\hline & $2(n=34)$ & $62-108$ & 86,50 & $79,25-93,50$ \\
\hline & $3(n=37)$ & $82-114$ & 98 & $94-104$ \\
\hline & $4(n=30)$ & $71-117$ & 99,50 & $93-106,25$ \\
\hline & $5(n=32)$ & $90-120$ & 102 & $97-106,25$ \\
\hline Total & $n=382$ & $48-120$ & 87,50 & $81,20-95,42$ \\
\hline
\end{tabular}

Fonte: elaborado pelas autoras 
Evidências preliminares de talento musical em crianças na educação básica

Fabiana Oliveira Koga • Rosemeire de Arauljo Rangni

Os resultados estatisticamente significantes permitem concluir a necessidade de diferentes versões do PSHM para cada ano escolar.

\section{Considerações finais}

O PSHM apresentou indicativos de sua capacidade de mensuração em decorrência de seus resultados apresentados. No entanto, verifica-se a necessidade de continuar os procedimentos psicométricos como a validação, a confiabilidade e a fidedignidade, inclusive o pareamento com algum teste já existente. A aplicação em diferentes realidades e em um maior contingente de participantes permitirá verificar, de fato, os níveis de sensibilidade para mensuração do PSHM.

Nas análises apresentadas foi possível constatar a necessidade de diferentes versões, respeitando os anos escolares, além de uma versão para a rede pública e outra para a rede privada, isso porque na rede particular há a presença do professor de educação musical.

Quanto mais o PSHM for utilizado, mais sua validade poderá ser verificada, inclusive, seu uso pelos professores da educação básica poderá assegurar a capacidade da usabilidade. É imperioso mencionar que o instrumento precisa funcionar com qualquer estudante (participante) e com qualquer aplicador interessado em rastrear o talento musical.

A realidade da educação musical brasileira permite apontar que há negligências com a identificação do talento, em específico na educação básica. Por essa razão, é preciso encorajar os professores e formá-los adequadamente. Dessa forma, pode haver oportunidades para as crianças talentosas e seus pares não ficarem à margem de seu desenvolvimento musical. 


\section{Notas}

1 A Política Nacional de Educação Especial na Perspectiva da Educação Inclusiva (BRASIL, 2008) utiliza o termo "altas habilidades/ superdotação", contudo, nesse texto, empregar-se-á o termo "talento" devido ao embasamento teórico na área musical, de que trata essa pesquisa.

2 El talento se caracteriza por la aptitud de producir grandes cosas, pero las cuales se mantienen dentro del marco de lo ya conseguido hasta entonces (RUBINTEIN, 1967, p. 711).

3 Com base no dicionário Webster's (HOUAISS, 2007).

4As análises foram realizadas utilizando dois softwares de estatística: Instat (https://www.statistics.com/software-directory/ instat) e Statistical Package for the Social Sciences (https://www. osbsoftware.com.br/fabricante/ibm/?gclid=CjwKCAjw9L_tBRBXEiw AOWVVCcMezXx5HxiYHCWVEnIAS7DT-2y43NIfgP6RB7T4SXTYZoU uPjp8bxoCggAQAvD_BwE).

5 A seleção da $8^{a}$ escola vinculou-se ao aceite da equipe gestora para a realização dos dois momentos. As demais escolas argumentaram falta de tempo em sua carga horária para a realização de duas aplicações do PSHM.

\section{Referências}

BRASIL. Ministério da Educação. Lei de Diretrizes e Bases da

Educação Nacional. Brasília, 20 dez. 1996. Disponível em: http://www. planalto.gov.br/ccivil_03/LEIS/L9394.htm. Acesso em: 18 set. 2019.

BRASIL. Política Nacional de Educação Especial na Perspectiva da

Educação Inclusiva. Brasília, 2008. Disponível em: http://portal.mec. gov.br/arquivos/pdf/politicaeducespecial.pdf. Acesso em: 30 out. 2019. BRASIL. Ministério da Educação. Lei de Diretrizes e Bases da

Educação Nacional. Brasília, DF: Ministério da Educação, 29 dez. 
Evidências preliminares de talento musical em crianças na educação básica Fabiana Oliveira Koga • Rosemeire de Arauljo Rangni

2015. Disponível em: http://www.planalto.gov.br/ccivil_03/_Ato20152018/2015/Lei/L13234.htm\#art2. Acesso em: 18 set. 2019.

BRASIL. Ministério da Educação. Ensino de música será obrigatório. Brasília, DF: Ministério da Educação, 02 de maio de 2016. Disponível em: http://www.planalto.gov.br/ccivil_03/_Ato2015-2018/2016/Lei/ L13278.htm. Acesso em: 18 set. 2019.

BENITO, Yolanda. La identificación: procedimiento e instrumentos. In: ALONSO, J. A.; RENZULLI, J. S.; BENITO, Y. (org.). Manual Internacional de Superdotados. Madrid: EOS, 2003, p. 33-69.

BORLAND, James. H.; WRIGHT, Lisa. Identifying young, potentially gifted, economically disadvantages students. In: RENZULLI, J. S. (org). Identification of students for gifted and talented programs. Estados Unidos: Corwin Press, 2004, p. 25-42.

BRUNI, Adriano. L. PASW aplicado à pesquisa acadêmica. São Paulo: Atlas, 2011. 251 p.

FARIAS, Eliana. S.; WECHSLER, Solange. M. Desafios na identificação de alunos intelectualmente dotados. In: VIRGOLIM, Ângela, M. R.; KONKIEWITZ, Elizabeth. C. (org). Altas Habilidades/Superdotação, inteligência e criatividade. Campinas: Papirus, 2014. p. 335-350. FIELD, Andy. Descobrindo a estatística usando o SPSS. 2. ed. Porto Alegre: Artmed, 2009. 679 p.

FEITOSA, Maria Ângela G.; Teoria e métodos em Psicofísica. In: PASQUALI, Luiz. Instrumentação Psicológica: fundamentos e práticas. Porto Alegre: Artmed, 2010. p. 79-103.

FREITAS, Soraia. N.; PEREZ, Susana. G. P. B. Altas habilidades/ superdotação: atendimento especializado. 2. ed. Marília: ABPEE, 2012. $140 \mathrm{p}$.

GORDON, Edwin. E. Teoria da aprendizagem musical: competências, conteúdos e padrões. Lisboa: Fundação Calouste Gulbenkian, 2000. 518 p. HAROUTOUNIAN, Joanne. Kindling the spark: recognizing and developing musical talent. New York: Oxford University Press, 2002. 366 p. 
Evidências preliminares de talento musical em crianças na educação básica Fabiana Oliveira Koga • Rosemeire de Arauljo Rangni

HOUAISS, Antonio. Webster's: dicionário universitário. 6ª ed. Rio de Janeiro, 2007. 889 p.

KIRNARSKAYA, Dina. The natural musician: on abilities, giftedness and talent. Trad. do russo por Mark H Teeter. New York: Oxford, 2004. 411 p. KIRNARSKAYA, Dina. How to Predict Professional Success in Music and Beyond? Constructing Universal Talent's Structure for the Best Vocational Choices. Japão: The international academy forum, 2013. 14 p. KOGA, Fabiana de Oliveira. Protocolo para Screening de Habilidades Musicais. 2019. 250f. Tese (Doutorado em Educação) - Faculdade de Filosofia e Ciências, Universidade Estadual Paulista, Marília, 2019. Disponível em: https://repositorio.unesp.br/handle/11449/182213. Acesso em: 07 out. 2019.

KOGA, Fabiana de Oliveira; CHACON, Miguel. C. M. Ângela: foi apenas uma questão de oportunidade e enriquecimento. In: CONGRESSO BRASILEIRO DE EDUCAÇÃO, 6., 2017, Bauru. Anais [...]. Bauru: UNESP/ FC/Departamento de Educação, 2017. Comunicação oral. Disponível em: http://www.cbe-unesp.com.br/2017/pages/anais_cbe_v01.pdf. Acesso em: 30 out. 2019.

MANNING, Sidney A. Psicofísica clássica e métodos escalares. São Paulo: EPU, 1974. 114 p.

PASQUALI, Luiz. Escalas Psicométricas. In: PASQUALI, L. Instrumentação Psicológica: fundamentos e práticas. Porto Alegre: Artmed, 2010, p. 116-135.

PASQUALI, Luiz. Psicometria: teoria dos testes na psicologia e na educação. 5. ed. Petrópolis: Vozes, 2013. 397 p.

RENZULLI, Joseph S.; REIS, Sally M. The schoolwide enrichment model: a comprehensive plan for education excellence. 3. ed. Connecticut: Creative Learning Press, 2014. 426 p.

RENZULLI, Joseph S. A concepção de superdotação no modelo dos três anéis: um modelo de desenvolvimento para a promoção da produtividade criativa. In: VIRGOLIM, Ângela M. R.; KONKIEWITZ, Elizabeth C. (org). Altas Habilidades/Superdotação, inteligência e criatividade. Campinas: Papirus, 2014, p. 219-264. 
Evidências preliminares de talento musical em crianças na educação básica Fabiana Oliveira Koga • Rosemeire de Arauljo Rangni

ROEDERER, Juan G. Introdução à física e Psicofísica da música. São Paulo: Editora da Universidade de São Paulo, 2002. 307 p.

RUBINSTEIN, John L. Princípios de Psicologia general. Trad. Sarolta Trowsky. México: Grijalbo, 1967. 758 p.

SEASHORE, Carl E. Psychology of music. Estados Unidos: McGraw-Hill, 1938. $437 \mathrm{p}$.

SEVERINO, Antônio J. Metodologia do Trabalho científico. 23 ed. São Paulo: Cortez, 2007. 304 p.

SLOBODA, John A. A mente musical: psicologia cognitiva da música. Trad. Beatriz Ilari e Rodolfo Ilari. Londrina: EDUEL, 2008. 265 p.

TEPLOV, Boris M. Psychologie des aptitudes musicales. Paris: Press universitaires de france, 1966. 222 p.

VIEIRA, Sonia. Estatística básica. 2ª ed. São Paulo: Cengage, 2018. 254 p. 